\title{
NEW MEDICAL-SURGICAL BUILDING OF THE ONTARIO VETERINARY COLLEGE
}

\begin{abstract}
$\mathrm{T}$ HE new medical-surgical building of the Ontario Veterinary College was opened recently by two ministers of the Province, the Minister of Agriculture, the Honourable W. A. Goodfellow, and the Minister of Public Works, the Honourable T. R. Connell. In Canada and the United States there is a division of responsibilities for certain service between the federal and the local government, and in both countries education is a local responsibility and provided by the Province or the State. The College was founded in Toronto as a private institute in 1862 by Andrew Smith, a graduate of the Royal Dick Veterinary College in Edinburgh, and was acquired by the Government of Ontario in 1908. It was affiliated to the University of Toronto at that time and was transferred to Guelph in 1922. The present dean, Dr. T. Lloyd Jones, a Welsh-born Canadian, was appointed in 1952. Dr. Jones has done a great deal to improve the teaching and research facilities of the College. $\mathrm{He}$ is interested in the broad field of veterinary education, has travelled in the United States, South America, India and Europe, to study this subject and has acted as a consultant on international problems in veterinary education.
\end{abstract}

The new buildings provide incomparable facilities for teaching clinical subjects ; the older accommodation has also been retained for housing animals for disease investigation, thus greatly increasing the available animal space. To provide a similar building in Britain would cost about one million pounds. Facilities for teaching the preclinical subjects are provided on the same generous scale, and it is proposed to re-house some of these departments in the next few years. Generally, the veterinary schools in North America are on a more lavish scale than those in Britain. At Guelph the new accommodation brings the college to a very high level even by American standards. There is only one other college in Canada, at St. Hyacinthe, Quebec, where instruction is given in French.

The College is affiliated to the University of Toronto, but its administration is vested largely in the dean and the Veterinary Faculty, with responsibility to the Ministry of Agriculture. Courses of study are submitted to the Senate of the University of Toronto. As a result of the growing demand for university education in Canada, the educational institutes at Guelph may, in the not too distant future, attain full university status. If this takes place it would be a reversal of the pattern so common in Britain where arts and humanities so often precede the science subjects. Guelph would be unique in having veterinary science as its oldest faculty, 1862, followed by agriculture twelve years later. This latter has developed into a very large faculty comprising large units for each of its component subjects. Guelph and Toronto are about sixty miles apart, but this distance has not prevented close collaboration between members of the medical and veterinary professions in a number of research subjects. For many years there has been a close liaison between the Department of Physiology of Toronto Medical School and the Surgery Department of the Veterinary
College. In the more recent past a joint team of medical and veterinary workers has carried out an investigation on atherosclerosis and studied the effect of certain phospholipids in experimental work on pigs.

The new building is constructed in red rustic brick and modern building materials have been utilized in the floors, walls and ceilings, each suitably selected for function but designed in such a way that æsthetics and function combine to form a most attractive building. Those who planned the buildings studied the layout of a number of clinical departments. They were able to avoid the faults which experience had brought to light in several schools. There are several operating theatres equipped for large animals and a number of small animal theatres all serviced by central sterilization. The $\mathrm{X}$-ray equipment is specially designed for large animals and has special Buckie screens for use with horses and cattle. A large therapy unit is also available. Housing has been provided for all types of animals, and the small animal unit is up to the standard of a modern hospital and is air-conditioned throughout.

In meeting the cost of this magnificent new building the Provincial Department of Agriculture has recognized the great contribution that can be made and has been made by the veterinary profession on an increasing scale to the economy of the country This type of clinical department is particularly essential in veterinary schools where the teaching material cannot be provided in existing hospitals.

\section{Eleventh Annual Convention of the Canadian Veterinary Medical Association}

The Convention, held in the Ontario Veterinary College, was attended by more than six hundred veterinarians from Canada, the United States, Great Britain, South America and the Caribbean area. The visitors included practitioners, federal and provincial workers, and those interested in research, education and public health. Meetings were held in the new hall and in the Agricultural College buildings. In a presidential address, Dr. J. N. Henderson, professor of clinics, expressed the view that great changes were taking place in agriculture, that farming was no longer a way of life but was becoming a means of earning a living and that small units would have to merge to form a unit that would give a financial return comparable with other occupations. The veterinary profession would have to train graduates who were fully aware of economic factors in animal production and be able to provide an appropriate professional service.

There were papers on many aspects of modern surgical techniques in large and small animals and an up-to-date review of the application of radiology to veterinary practice. Fundamental aspects of bacteriology and virology were discussed, and papers dealt with the zoonoses with particular reference to government participation in schemes of control. The role of the profession in the civil defence programme was outlined. The structure of the poultry industry in North America has changed 
radically during the past ten years and the role of the profession in these new circumstances was discussed. While there is a general acceptance that the medical and veterinary professions have a great deal in common in teaching and research, the main divergence arises at the point of application to their respective patients. Economic considerations are of greatest influence in the poultry industry, where a setback in rearing birds may represent the difference between a profit and a loss ; there are similar considerations with all the farm animals and it is only with pet animals that sentiment replaces economic considerations. The diverse problems arising in controlling rabies were discused and a film was shown of clinical cases of rabies in dogs, cats and cattle. In North America there is a reservoir of infection in wild life-foxes, wolves, skunks-and relatively few cases in dogs. In Trinidad there is a vastly different problem where vampire and other bats act as reservoirs and the epizootic pattern in cattle varies with the disease position in colonies of bats. These colonies break up and disperse when furious rabies develops and causes infection in cattle in new areas. In Great Britain dogs and cats entering the country are held in quarantine for six months and it is clear that this is a small price to pay for freedom from this disease. There were three British veterinarians present who contributed to the proceedings. J. N. Ritchie, chief veterinary officer of Great Britain, presented a paper which surveyed the present position of the veterinary services in Britain, and W. L. Weipers, of the University of Glasgow, reviewed developments in veterinary education. D. D. Lawson, of the University of Glasgow, presented a paper on thoracic surgery and gave a televised demonstration of volatile anæsthesia in the cow and the dog.

This Convention provides a forum for the discussion of scientific and administrative matters which affect the profession in Canada. As Guelph is the alma mater of the majority of veterinarians who live in Canada, the meeting in this city also took on the character of an alumnus reunion and the social functions were very well attended.

\section{CONTROL OF GOVERNMENT RESEARCH AND DEVELOPMENT EXPENDITURE IN BRITAIN}

\begin{abstract}
$\mathrm{T}$ THE seventh special report from the Select Committee on Estimates for the session 1958-59* contains the observations of the Treasury on the sixth report from the Select Committee for the session 1957-58 dealing with Treasury control of expenditure (see Nature, 182, 1467 ; 1958). While the Treasury agrees with the Committee's general analysis and many of its comments on particular points, the Treasury suggests that in some respects the Committee's conclusions imply some misconceptions of what is needed, what is possible and what is in fact done. It is claimed that the theory of departmental responsibility and partnership has been steadily pursued under successive Governments for about forty years, and the Treasury does not agree that, while new expenditure may be carefully watched, continuing expenditure may escape relatively unchallenged. Although the main responsibility for vigilant watching for economy in continuing expenditure rests, and must rest, with the spending Department, the Treasury does in fact supplement the Department's own efforts by maintaining a constant watch on continuing expenditure, as well as by bringing particular areas of such expenditure under special review from time to time. A high proportion of the Treasury's time is in fact devoted to considering such continuing expenditure.
\end{abstract}

On the Committee's suggestion that eventual commitments are inadequately assessed, the Treasury points out that a wide degree of uncertainty must often remain as to the eventual cost of research policies or major developments involving the solution of scientific and technical research problems; the comment is made that it is unrealistic to suppose that some alteration of financial technique in the Treasury could avoid such difficulties. Secondly, the Treasury

* Seventh Special Report from the Select Committee on Estimates Session 1958-59. Treasury Control of Expenditure (Observations of the net. points out that forecasts of all civil expenditure, up to three years ahead, have in fact been prepared annually for many years past, and play a very important part in the general control of Government expenditure. Without claiming that the technique of 'forward looks' is yet as fully developed or effectively exploited as it might be, the Treasury points out that Ministers are able to decide how far it is necessary to review existing policies reflected in the forecasts, and to adjust new policies which they may have had in mind, to contain the total of Government expenditure within acceptable limits. In devoting further attention to this matter, the Tressury undertakes, however, to have full regard to the Committee's comments. Again, while the Treasury agrees generally with the Committee as to the importance of prior sanction control, and also that the limits of delegated authority should be periodically reviewed as is at present done, it does not interpret the Committee's report as recommending in general any major change in the existing policy. It agrees with the Committee's view that delegation so far as is compatible with the reservation to the Chancellor of the Exchequer of the power to discharge effectively his own essential responsibilities is primarily an attitude of mind which should lead to action whenever opportunity offers ; but the three criteria suggested by the Select Committee in this connexion are regarded neither as a complete guide nor, within the ground they cover, as a wholly reliable one.

The Select Committee on Estimates had recommended specifically that a small independent committee, which should have access to Cabinet papers, should be appointed to report upon the theory and practice of Treasury control of expenditure. This recommendation the Treasury does not accept, and the report sets forth at some length the reasons why the Government is not prepared to accept the recommendation; although in view of the Committee's 